\title{
Pattern of Alteration in Foot Mechanics When Carrying Loads Unilaterally in Hand
}

\author{
Deepashini Harithasan \\ Universiti Kebangsaan Malaysia, deepa_shini@hotmail.com \\ Baharudin Omar \\ Universiti Kebangsaan Malaysia, baharudinhjomar@gmail.com
}

Aatit Paungmali

Chiang Mai University, aatitpaungmali@gmail.com

Follow this and additional works at: https://nsuworks.nova.edu/ijahsp

Part of the Musculoskeletal System Commons, Physical Therapy Commons, and the Physiotherapy Commons

\section{Recommended Citation}

Harithasan D, Omar B, Paungmali A. Pattern of Alteration in Foot Mechanics When Carrying Loads Unilaterally in Hand. The Internet Journal of Allied Health Sciences and Practice. 2017 Jan 01;15(2), Article 7.

This Manuscript is brought to you for free and open access by the College of Health Care Sciences at NSUWorks. It has been accepted for inclusion in Internet Journal of Allied Health Sciences and Practice by an authorized editor of NSUWorks. For more information, please contact nsuworks@nova.edu. 


\title{
Pattern of Alteration in Foot Mechanics When Carrying Loads Unilaterally in Hand
}

\begin{abstract}
PURPOSE: Carrying weight in one hand is a common functional activity. This study investigated the effects of incremental loads carried in one hand unilaterally and its influence on the foot mechanics [plantar pressure, maximum force and contact area]. METHOD: Twenty healthy individuals were tested, in standing and walking, while carrying different weights (no load, $5 \mathrm{~kg}, 7.5 \mathrm{~kg}$ and $10 \mathrm{~kg}$ ) using their right hand. ANCOVA was conducted separately for the right and left leg to address the effect of incremental loads on the foot mechanics within each leg with navicular drop index and $Q$ angle as covariates. Paired $t$-test was conducted to address the effect of different loads on the foot mechanics between the legs. RESULTS: Results showed a significant increase in plantar pressure (pCONCLUSION: The fundamental changes in foot mechanics under the influence of different loads may be used to interpret the changes seen in the foot mechanics among different pathological condition.
\end{abstract}

\section{Author Bio(s)}

Deepashini Harithasan is a PhD student at Faculty of Heath Science, Department of Biomedical Science, University Kebangsaan Malaysia.

Baharudin Omar is a Professor from Department of Biomedical Science, Faculty of Health Science, University Kebangsaan Malaysia. He is also the Dean of Faculty of Health Science.

Aatit Paungmali is a Professor from Department of Physical Therapy, Faculty of Associated Medical Sciences, Chiang Mai University.

\section{Acknowledgements}

None declared 


\title{
TIAHSP

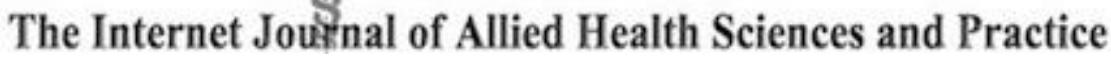

Dedicated to allied health professional practice and education

Vol. 15 No. 2 ISSN 1540-580X

\section{Pattern of Alteration in Foot Mechanics When Carrying Loads Unilaterally In Hand}

\author{
Deepashini Harithasan, PT, DPT \\ Baharudin Omar, PT, DPT, EdD \\ Aatit Paungmali, PT, PhD, CAPS \\ Universiti Kebangsaan Malaysia \\ Chiang Mai University \\ Malaysia
}

\begin{abstract}
PURPOSE: Carrying weight in one hand is a common functional activity. This study investigated the effects of incremental loads carried in one hand unilaterally and its influence on the foot mechanics [plantar pressure, maximum force and contact area]. METHOD: Twenty healthy individuals were tested in standing and walking while carrying different weights (no load, $5 \mathrm{~kg}, 7.5 \mathrm{~kg}$ and $10 \mathrm{~kg}$ ) using their right hand. An ANCOVA was conducted separately for the right and left leg to address the effect of incremental loads on the foot mechanics within each leg with navicular drop index and $Q$ angle as covariates. A paired $t$-test was conducted to address the effect of different loads on the foot mechanics between the legs. RESULTS: Results showed a significant increase in plantar pressure $(p<.05)$, maximum force $(p<.05)$, and contact area $(p<.05)$ in the right leg while standing. While walking, the results demonstrated a significant increase in plantar pressure $(p<.05)$ and maximum force $(p<.05)$ in the right leg. In addition, carrying loads of $7.5 \mathrm{~kg}$ and $10 \mathrm{~kg}$ during standing and $7.5 \mathrm{~kg}$ during walking caused an increase in plantar pressure and maximum force on the right leg. CONCLUSION: The fundamental changes in foot mechanics under the influence of different loads may be used to interpret the changes seen in the foot mechanics among different pathological condition.
\end{abstract}

\section{INTRODUCTION}

The human foot plays a fundamental role by providing sensory information in regards to the foot contact with the ground during static and dynamic activity. ${ }^{1,2}$ The anatomical and physiological characteristics of the foot can cause an alteration in foot mechanics such as plantar pressure (PP), maximum force (MF) and contact area (CA) during static and dynamic activities. ${ }^{3}$ Knowledge of foot mechanics is important in the assessment of various foot pathologies which can be further addressed in clinical practice. ${ }^{4,5}$ Studies suggested that standing and walking with load increases the load carried by the musculoskeletal system, which further leads to alteration in the foot mechanics. ${ }^{6,7}$

Many studies reported changes in the ground reaction forces when carrying loads. ${ }^{7-10} \mathrm{~A}$ past study reported a $10 \%$ increase of ground reaction force when carrying $32 \mathrm{~kg}$ of loads. ${ }^{8}$ Another study reported an increase in ground reaction force with an increase of $8 \mathrm{~kg}$ of loads. ${ }^{9} \mathrm{It}$ is reported that a load of $15 \%$ of one's body weight affects the trunk movement and causes gait alteration. ${ }^{11}$ When climbing stairs, a load of $10 \%$ or more can cause trunk inclination and an increase in maximum force during ascending stairs. ${ }^{12}$ It is a common that lower limb injuries occur as a consequence of carrying heavy loads because of the increase of ground reaction forces. Past studies have reported that heavy loads contribute to metatarsal stress fractures, the onset of plantar fasciitis, an increase in knee pain, and foot blisters. 8,9 As the abnormal force imposed over the plantar surface of the foot may be an important factor in the development of many of the mentioned injuries, the knowledge and understanding of the ground reaction force or the changes in the foot mechanics may help in better understand these pathological conditions as well as prevent and treat them in an earlier phase. In addition, it is generally believed that asymmetric carrying or side-to-side carrying is more harmful than symmetric carrying. A past study reported that asymmetric load carrying places greater stress on internal tissues compared to symmetric load carrying methods. ${ }^{13}$ However, very limited studies have looked into the asymmetric carrying methods. 
A study on the effect of bag holding using one hand reported that there is an increase in lower leg muscle activity on the same side of the load carried. ${ }^{14}$ Nevertheless, no information is available on the change in foot mechanics when carrying weight on one hand unilaterally. When a bag is carried with one hand and its weight exceeds a specific weight, the center of gravity position of the whole body shifts towards the center of the bag..$^{15}$ Such shift of gravity may cause uneven distribution of pressure and force to the lower limb, thus placing greater loads on the musculoskeletal system, which may lead to further leg injury and pain. ${ }^{13}$ However, less attention has been paid to understand how carrying weight with one hand acts on foot mechanics in terms of PP, MF, and CA while standing and walking.

The current study investigated the effect of carrying weight with one hand unilaterally and its influence on the PP, MF, and CA. Firstly, the effect of incremental loads on PP, MF, and CA within each leg were investigated. Secondly, the effect of different loads on PP, MF, and CA between right and left legs was examined. Thirdly, the effects of covariates such as the navicular drop index (NDI) and $Q$ angle (measurement of the angle between the quadriceps muscles and the patella tendon) on PP, MF, and CA were scrutinized. However, before clinicians can make a decision for patients with foot disorders, it is important to understand that foot mechanics vary in healthy individuals. Therefore, healthy individuals were selected in this study to understand the fundamental changes in foot mechanics under the influence of different loads. The known theory can be used to interpret the changes seen in the foot mechanics among different pathological condition in future studies.

\section{MATERIALS AND METHODS}

\section{Participants}

This is a cross-sectional study. A total of 20 healthy individuals ( 10 males and 10 females) aged between 30 and 55 years participated in this study. Prior to the data collection, subjects were screened for normal BMI ranging from $18.50 \mathrm{~kg} / \mathrm{m}^{2}$ to 24.99 $\mathrm{kg} / \mathrm{m}^{2}$ to standardize the BMI of the participants. The mean (SD) age was $43.55( \pm 14.57)$ years, weight was $62.59( \pm 8.73) \mathrm{kg}$, height was $162.68( \pm 5.40) \mathrm{cm}$ and BMI was $23.66( \pm 3.13)$, respectively. The mean (SD) NDI in male was $6.3( \pm 1.8) \mathrm{mm}$ and in female was $6.2( \pm 1.6) \mathrm{mm}$, respectively. While the $Q$ angle in males was $9.00( \pm 2.10)$ degree and in females was $13.00( \pm 2.90)$ degree, respectively. Participants were all right-hand and right-leg dominant (by self-report, based on which side the participants prefer during performing certain tasks such as throwing the ball and kicking the ball). Ethical approval was granted by the institutional review board according to the Declaration of Helsinki. Participants provided written informed consent prior to data collection which clarified the purpose and the procedures of the study.

\section{Equipment}

Plantar pressure [PP $(\mathrm{kPa})]$, maximum force [MF (\% of body weight, \%BW)], and contact area [CA $\left.\left(\mathrm{cm}^{2}\right)\right]$ were measured using TekScan Mat Scan Pressure Assessment Systems, Sensor Matscan Version 6.3 (TekScanlnc, South Boston, USA). This system comes with a floor mat embedded with sensors that were made up of over 2,000 individual pressure-sensing locations. The system consists of a $5 \mathrm{~mm}$ thick floor mat $(432 \times 368 \mathrm{~mm})$. The sensors are referred as "sensing elements" or "sensels" that are arranged in rows and columns on the sensor. The Matscan sensor detects the participants PP, MF, and CA. The MatScan system software is compatible with various versions of Microsoft systems and can be used to perform simple calibrations. The calibration procedure was performed for all participants before recording where the participants need to stand on the sensor for a moment. Each mat was calibrated individually.

\section{Measurement protocol}

PP, MF, and CA were measured under two conditions: standing and walking barefoot. Participants were instructed to stand and walk with no load, carrying a $5 \mathrm{~kg}$ load, a $7.5 \mathrm{~kg}$ load, and a $10 \mathrm{~kg}$ load using the right hand with the arm hanging straight down. Before the data was collected, participants were given 10 minutes to familiarize themselves with the platform after a short demonstration by the researcher. Familiarization was performed following the actual procedure for data collection. For the standing trial, participants were instructed to stand on the platform while looking straight ahead and visually fixate on a black dot that was placed at eye level. Meanwhile, for the walking trial, participants were instructed to walk following the two-step protocol. ${ }^{16}$ The twostep protocol requires participants to strike the sensor on the second step (standardized to right foot) once reaching a constant velocity. ${ }^{17}$ Thus, the second (right foot) and the third step (left foot) were taken. The two-step protocol is suggested to reproduce plantar force and pressure data that is reflective of foot function during gait. ${ }^{17}$ Participant walked at a moderate speed of $1.34 \mathrm{~m} / \mathrm{s}$ as this speed was reported as the average speed that an individual walked when they were permitted to walk freely over the ground.18 Walking speed was monitored concurrently with a single event stopwatch (Sportsmith, Tulsa Oklahoma). All the participants were instructed to walk at the same speed in order to control for potential confounding influences because of different walking speed.

() The Internet Journal of Allied Health Sciences and Practice, 2017 
Once the participants were comfortable with the familiarization procedure, the actual data collection was recorded. Participants were first told to stand on the platform without any load followed by standing on the platform while carrying three different weights: $5 \mathrm{~kg}, 7.5 \mathrm{~kg}$, and $10 \mathrm{~kg}$, respectively using their right hand. The walking trial was recorded with no load followed by carrying weights of $5 \mathrm{~kg}, 7.5 \mathrm{~kg}$, and $10 \mathrm{~kg}$ load, respectively, using their right hand. The recorded data was considered successful when participant's foot hit the platform on the second step; participants did not look down at the platform and did not pause while walking on the platform. Participants were given a 10-minute break between each task. The PP, MF, and CA for the right foot and left foot while carrying loads using the right hand were recorded for analysis. In each condition, three measurements for each weight were recorded in both the legs, which has shown a good level of consistency. ${ }^{3}$ Prior to the current study, the reliability of the study protocol of using PP measurement was established (ICC ranged from 0.95 to 0.98 ). ${ }^{4}$ In addition, the NDI and Q angle in the right leg were measured as a covariate.

Brody's navicular drop test was done on all the participants in both weight bearing and non-weight bearing positions. The weight bearing arch height was obtained with the participants standing on the floor with both feet apart at the level of the shoulder. The non-weight bearing arch height was obtained with the participants sitting on a chair with hip and knee flexed to 90 degrees and the foot placed flat on the ground. A marker pen was used to mark the skin over the most prominent point of the navicular tuberosity. A blank paper was used to mark the navicular height in weight bearing and non-weight bearing positions, using the mark on the skin as a reference mark. The difference of navicular drop in weight bearing and non-weight bearing was calculated. ${ }^{19}$

Q-angle was defined as the angle created by the intersection of 2 lines at the knee: one connecting the ASIS and the center of the patella, and the other connecting the center of the patella and the tibial tuberosity. Participants were in a supine position while the investigator used visual inspection and palpation to identify and then label the 3 landmarks. A manual extendable-arm goniometer was positioned with the axis over the center of the patella, one arm over the ASIS, and the other arm over the center of the tibial tuberosity and the $\mathrm{Q}$-angle was measured. ${ }^{20}$

\section{Data Analysis}

Statistical analysis was performed using SPSS 20.0 for Windows (SPSS Inc, Chicago, III). The sample size for this study was calculated using the G-power software with a power of 0.80 and effect size of 0.60 , which resulted in 20 participants. A p-value of less than 0.05 was considered statistically significant. Normal distribution was tested using Shapiro-Wilk Test. An ANCOVA was conducted separately for the right and left leg to address the effect of incremental loads (no load, $5 \mathrm{~kg}, 7.5 \mathrm{~kg}$, and $10 \mathrm{~kg}$ ) on the $\mathrm{PP}, \mathrm{MF}$, and CA in standing and walking conditions while carrying loads using the right hand. Bonferroni adjustments were applied for the post-hoc comparisons to account for multiple comparisons testing if the ANCOVA indicated a significant difference. Additionally, an ANCOVA was used to investigate the effect of potential factors that may affect the PP, MF, and CA such as navicular drop index for sitting and standing and the $Q$ angle. The partial Eta square $\left(\eta^{2} p\right)$ was used to measure the effect sizes where $0.01,0.06$, and 0.14 are considered small, medium, and large effect sizes, respectively. ${ }^{21} \mathrm{~A}$ paired t-test was conducted to address the effect of different loads on PP, MF, and CA between the legs.

\section{RESULTS}

\section{Demographics details}

Table 1 and Table 2 present the mean (standard deviations) for PP, MF, and CA while standing and walking. Table 3 presents the repeated-measures ANOVAs results, $p$-values and effect size for PP, MF and CA when carrying weight with one hand unilaterally while standing and walking.

\section{Effect of PP, MF and CA while standing}

A significant change was observed in PP, MF, and CA for the right leg while undertaking an incremental load from no load, $5 \mathrm{~kg}$, $7.5 \mathrm{~kg}$, and $10 \mathrm{~kg}$. A significant change was observed in PP and MF for the left leg while undertaking an incremental load from no load, $5 \mathrm{~kg}, 7.5 \mathrm{~kg}$, and $10 \mathrm{~kg}$. The CA for the left leg demonstrated no significant effect when undertaking incremental loads (Table 3). The covariates, NDI and the Q-angle, were not significantly related to $P P(p>.05), M F(p>.05$,$) , and C A(p>.05)$.

When PP, MF, and CA in different loads were compared between the right and left leg conditions, results portrayed a significant increase in PP and MF in a load of $7.5 \mathrm{~kg}(p<.05)$ and $10 \mathrm{~kg}(p<.05)$ on the right leg when compared to the left leg (Figure 1). In addition, a significant increase in CA between the legs were observed in a load of $5 \mathrm{~kg}(\mathrm{p}<.05), 7.5 \mathrm{~kg}(\mathrm{p}<.05)$, and $10 \mathrm{~kg}(\mathrm{p}<.05)$ on the right leg when compared to the left leg.

\section{Effect of PP, MF and CA while walking}

A significant change was observed in PP and MF for the right leg while undertaking an incremental load from no load, $5 \mathrm{~kg}, 7.5 \mathrm{~kg}$, and $10 \mathrm{~kg}$. The CA for the right leg demonstrated no significant effect when undertaking incremental loads. A significant change

(c) The Internet Journal of Allied Health Sciences and Practice, 2017 
was observed in PP, MF, and CA for the left leg while undertaking an incremental load from no load, $5 \mathrm{~kg}, 7.5 \mathrm{~kg}$, and $10 \mathrm{~kg}$ (Table 3). The covariates, NDI and the $Q$-angle, were not significantly related to PP ( $p>.05), M F(p>.05)$, and CA ( $p>.05)$.

When the PP, MF, and CA in different loads were compared between the right and left leg, results showed a significant increase in PP in loads of $5 \mathrm{~kg}(\mathrm{p}<.05)$ and $7.5 \mathrm{~kg}(\mathrm{p}<.05)$ and a significant increase in MF in a load of $7.5 \mathrm{~kg}(\mathrm{p}<.05)$ on the right leg when compared to the left leg (Figure 2). In addition, a significant increase in CA between left and right legs were observed in a load of $7.5 \mathrm{~kg}(p<.05)$ on the left leg when compared to the right leg.

Table 1. Mean (SD) for plantar pressure, maximum force, and contact area while standing

\begin{tabular}{|l|l|l|l|l|l|}
\hline \multicolumn{2}{|c}{ Variables } & \multicolumn{1}{c|}{ No load } & \multicolumn{1}{c|}{$\mathbf{5} \mathbf{~ k g}$} & \multicolumn{1}{c|}{$\mathbf{7 . 5} \mathbf{~ k g}$} & \multicolumn{1}{c|}{$\mathbf{1 0 ~} \mathbf{~ g g}$} \\
\hline \multirow{3}{*}{ Right leg } & Plantar pressure (kPa) & $111.84(38.08)$ & $164.06(63.65)$ & $188.62(65.05)$ & $189.35(52.93)$ \\
\cline { 2 - 6 } & Maximum force (\%BW) & $51.83(13.55)$ & $77.98(11.69)$ & $92.93(14.08)$ & $96.34(13.07)$ \\
\cline { 2 - 6 } & Contact area (cm²) & $74.35(20.39)$ & $79.10(16.60)$ & $84.31(17.04)$ & $85.84(16.34)$ \\
\hline \multirow{3}{*}{ Left leg } & Plantar pressure (kPa) & $124.89(28.46)$ & $165.49(44.43)$ & $152.82(52.47)$ & $138.99(37.72)$ \\
\cline { 2 - 6 } & Maximum force (\%BW) & $58.66(11.14)$ & $73.33(19.50)$ & $66.89(15.71)$ & $66.56(14.08)$ \\
\cline { 2 - 6 } & Contact area (cm²) & $73.04(15.41)$ & $73.68(13.21)$ & $72.93(14.44)$ & $75.71(15.12)$ \\
\hline
\end{tabular}

Table 2. Mean (SD) for plantar pressure, maximum force and contact area while walking

\begin{tabular}{|l|l|l|l|l|l|}
\hline \multicolumn{2}{|c}{ Variables } & \multicolumn{1}{c|}{ No load } & \multicolumn{1}{c|}{$\mathbf{5} \mathbf{~ k g}$} & \multicolumn{1}{c|}{$\mathbf{7 . 5} \mathbf{~ k g}$} & \multicolumn{1}{c|}{$\mathbf{1 0 ~} \mathbf{~ g g}$} \\
\hline \multirow{3}{*}{ Right leg } & Plantar pressure (kPa) & $113.69(29.62)$ & $134.26(13.49)$ & $141.03(27.22)$ & $141.09(28.98)$ \\
\cline { 2 - 6 } & Maximum force (\%BW) & $63.57(10.36)$ & $71.04(12.25)$ & $75.99(10.51)$ & $76.02(11.77)$ \\
\cline { 2 - 6 } & Contact area (cm²) & $83.78(22.48)$ & $80.55(16.50)$ & $83.29(16.07)$ & $84.06(18.40)$ \\
\hline \multirow{3}{*}{ Left leg } & Plantar pressure (kPa) & $127.50(24.91)$ & $101.82(16.02)$ & $113.39(19.90)$ & $130.57(33.57)$ \\
\cline { 2 - 6 } & Maximum force (\%BW) & $62.48(10.21)$ & $67.51(6.72)$ & $71.00(11.09)$ & $75.94(10.63)$ \\
\cline { 2 - 6 } & Contact area (cm²) & $85.47(15.18)$ & $89.19(20.13)$ & $94.50(16.83)$ & $90.81(16.44)$ \\
\hline
\end{tabular}

Table 3. Repeated-measures ANOVAs results, $p$-values and effect size for plantar pressure, maximum force and contact area during carrying weight with one hand unilaterally in standing and walking

\begin{tabular}{|c|c|c|c|c|c|c|}
\hline Variables & $\begin{array}{l}\text { Plantar } \\
\text { pressure } \\
(\mathrm{kPa})\end{array}$ & Post hoc & $\begin{array}{c}\text { Maximum } \\
\text { force (\%BW) }\end{array}$ & Post hoc & $\begin{array}{c}\text { Contact } \\
\text { area }\left(\mathrm{cm}^{2}\right)\end{array}$ & Post hoc \\
\hline $\begin{array}{l}\text { Standing, } \\
\text { right leg }\end{array}$ & $\begin{array}{l}F(3,57)=16.35 \\
p<.05 \\
\eta^{2} p=0.46\end{array}$ & $\begin{array}{l}\text { No load }<5 \mathrm{~kg}^{*} \\
\text { No load }<7.5 \mathrm{~kg}^{*} \\
\text { No load }<10 \mathrm{~kg}^{*} \\
5 \mathrm{~kg}=7.5 \mathrm{~kg} \\
5 \mathrm{~kg}=10 \mathrm{~kg} \\
7.5 \mathrm{~kg}=10 \mathrm{~kg}\end{array}$ & $\begin{array}{l}F(3,57)=57.33 \\
p<.05 \\
\eta^{2} p=0.75\end{array}$ & $\begin{array}{l}\text { No load }<5 \mathrm{~kg}^{*} \\
\text { No load }<7.5 \mathrm{~kg}^{*} \\
\text { No load }<10 \mathrm{~kg}^{*} \\
5 \mathrm{~kg}<7.5 \mathrm{~kg}^{*} \\
5 \mathrm{~kg}<10 \mathrm{~kg}^{*} \\
7.5 \mathrm{~kg}=10 \mathrm{~kg}\end{array}$ & $\begin{array}{l}F(3,57)=18.86 \\
p<.05 \\
\eta^{2} p=0.50\end{array}$ & $\begin{array}{l}\text { No load }=5 \mathrm{~kg} \\
\text { No load }<7.5 \mathrm{~kg}^{*} \\
\text { No load }<10 \mathrm{~kg}^{*} \\
5 \mathrm{~kg}<7.5 \mathrm{~kg}^{*} \\
5 \mathrm{~kg}<10 \mathrm{~kg}^{*} \\
7.5 \mathrm{~kg}=10 \mathrm{~kg}\end{array}$ \\
\hline $\begin{array}{l}\text { Standing, } \\
\text { left leg }\end{array}$ & $\begin{array}{l}F(3,57)=6.74 \\
p<.05 \\
\eta^{2} p=0.26\end{array}$ & $\begin{array}{l}\text { No load<5 kg* } \\
\text { No load }=7.5 \mathrm{~kg} \\
\text { No load }=10 \mathrm{~kg} \\
5 \mathrm{~kg}=7.5 \mathrm{~kg} \\
5 \mathrm{~kg}>10 \mathrm{~kg} \\
7.5 \mathrm{~kg}=10 \mathrm{~kg}\end{array}$ & $\begin{array}{l}F(3,57)=6.42 \\
p<.05 \\
\eta^{2} p=0.25\end{array}$ & $\begin{array}{l}\text { No load }<5 \mathrm{~kg} \\
\text { No load }=7.5 \mathrm{~kg} \\
\text { No load }=10 \mathrm{~kg} \\
5 \mathrm{~kg}=7.5 \mathrm{~kg} \\
5 \mathrm{~kg}=10 \mathrm{~kg} \\
7.5 \mathrm{~kg}=10 \mathrm{~kg}\end{array}$ & $\begin{array}{l}F(3,57)=0.95 \\
p=0.42 \\
\eta^{2} p=0.05\end{array}$ & \\
\hline $\begin{array}{l}\text { Walking, } \\
\text { Right leg }\end{array}$ & $\begin{array}{l}F(3,57)=6.73 \\
p<.05 \\
\eta 2 p=0.26\end{array}$ & $\begin{array}{l}\text { No load }<5 \mathrm{~kg}^{*} \\
\text { No load }<7.5 \mathrm{~kg}^{*} \\
\text { No load }<10 \mathrm{~kg}^{*} \\
5 \mathrm{~kg}=7.5 \mathrm{~kg} \\
5 \mathrm{~kg}=10 \mathrm{~kg} \\
7.5 \mathrm{~kg}=10 \mathrm{~kg}\end{array}$ & $\begin{array}{l}F(3,57)=15.89 \\
p<.05 \\
\eta 2 p=0.46\end{array}$ & $\begin{array}{l}\text { No load }<5 \mathrm{~kg}^{*} \\
\text { No load }<7.5 \mathrm{~kg}^{*} \\
\text { No load }<10 \mathrm{~kg}^{*} \\
5 \mathrm{~kg}=7.5 \mathrm{~kg} \\
5 \mathrm{~kg}=10 \mathrm{~kg} \\
7.5 \mathrm{~kg}=10 \mathrm{~kg}\end{array}$ & $\begin{array}{l}F(3,57)=0.43 \\
p=0.74 \\
\eta^{2} p=0.02\end{array}$ & \\
\hline $\begin{array}{l}\text { Walking, } \\
\text { Left leg }\end{array}$ & $\begin{array}{l}F(3,57)=7.16 \\
p<.05 \\
\eta^{2} p=0.27\end{array}$ & $\begin{array}{l}\text { No load }>5 \mathrm{~kg}^{*} \\
\text { No load }=7.5 \mathrm{~kg} \\
\text { No load }=10 \mathrm{~kg} \\
5 \mathrm{~kg}=7.5 \mathrm{~kg} \\
5 \mathrm{~kg}<10 \mathrm{~kg} \\
7.5 \mathrm{~kg}=10 \mathrm{~kg}\end{array}$ & $\begin{array}{l}F(3,57)=14.17 \\
p<.05 \\
\eta^{2} p=0.43\end{array}$ & $\begin{array}{l}\text { No load }=5 \mathrm{~kg} \\
\text { No load }<7.5 \mathrm{~kg} \\
\text { No load }<10 \mathrm{~kg}^{*} \\
5 \mathrm{~kg}=7.5 \mathrm{~kg} \\
5 \mathrm{~kg}<10 \mathrm{~kg} \\
7.5 \mathrm{~kg}=10 \mathrm{~kg}\end{array}$ & $\begin{array}{l}F(3,57)=3.19 \\
p<.05 \\
\eta^{2} p=0.14\end{array}$ & $\begin{array}{l}\text { No load }=5 \mathrm{~kg} \\
\text { No load }<7.5 \mathrm{~kg} \\
\text { No load }=10 \mathrm{~kg} \\
5 \mathrm{~kg}=7.5 \mathrm{~kg} \\
5 \mathrm{~kg}=10 \mathrm{~kg} \\
7.5 \mathrm{~kg}=10 \mathrm{~kg}\end{array}$ \\
\hline
\end{tabular}

*The means difference is significant at the level of 0.05 


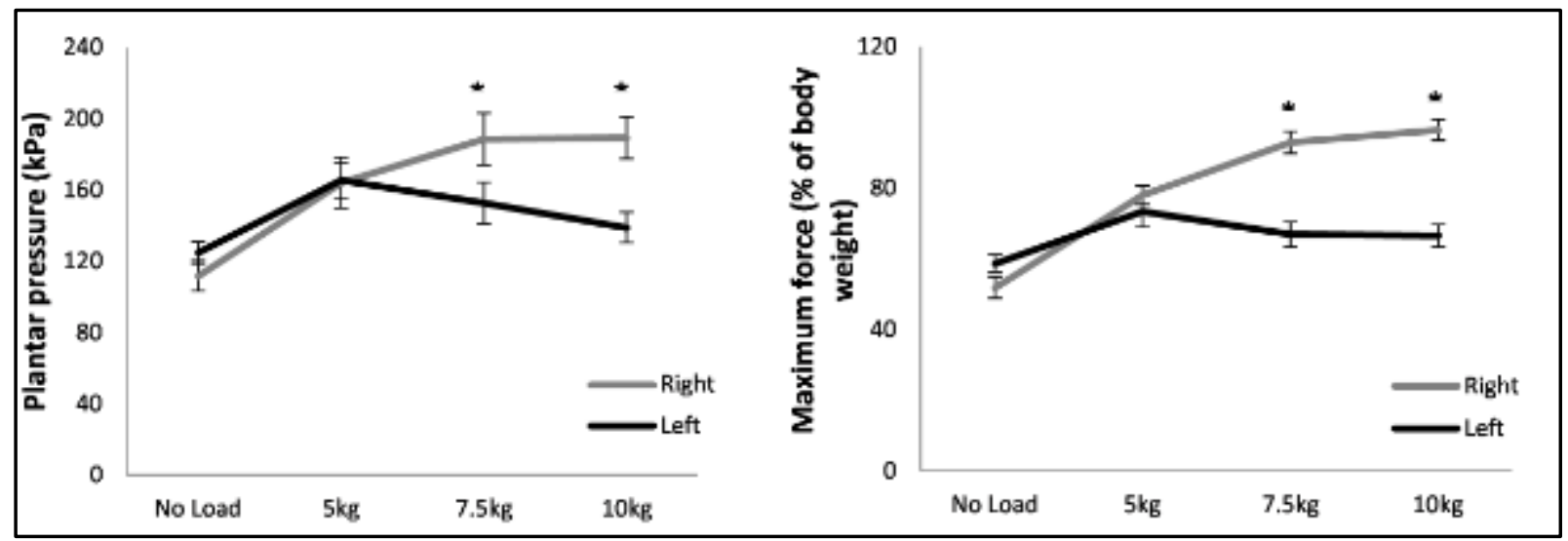

Figure 1. Influence of different loads on plantar pressure and maximum force in right leg and left leg during standing [Mean (Standard error of mean)]. *Statistically significant differences between right and left leg with $p<0.05$

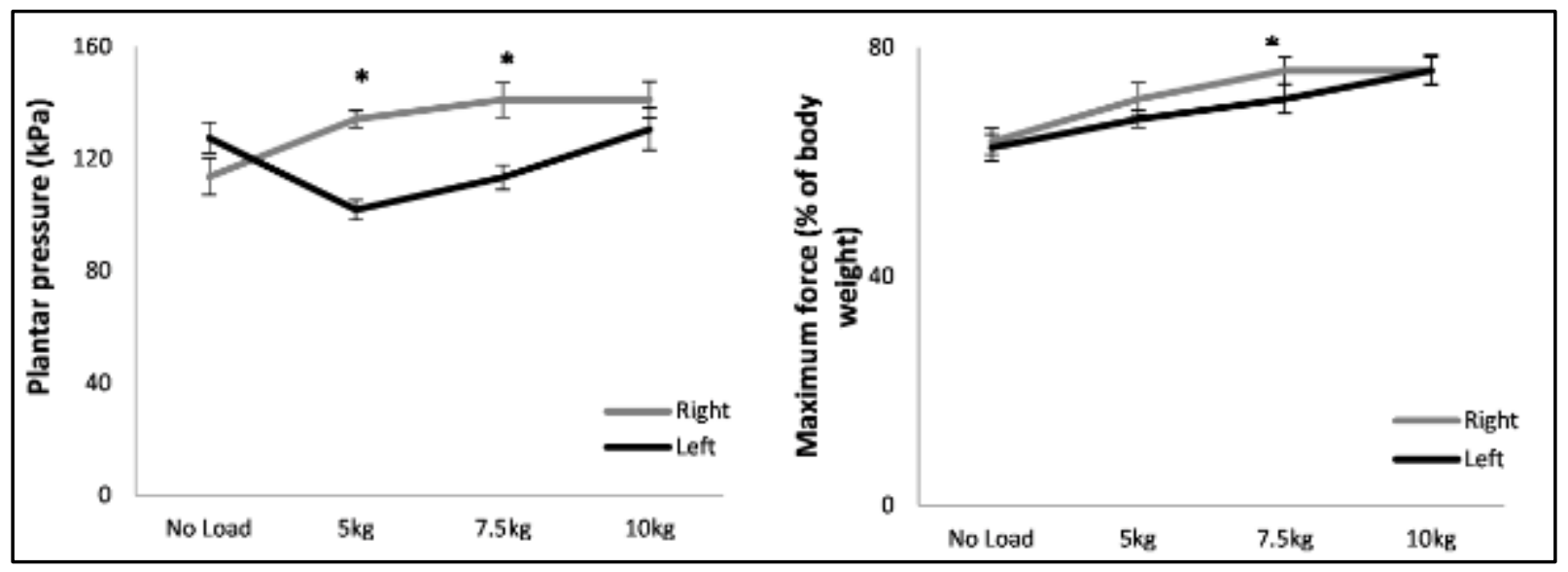

Figure 2. Influence of different loads on plantar pressure and maximum force in right leg and left leg during walking [Mean (Standard error of mean)]. *Statistically significant differences between right and left leg with $p<0.05$

\section{DISCUSSION}

The current study investigates the effect of incremental loads carried in one hand unilaterally and its influence on the foot mechanics during standing and walking. In particular, the effects of incremental loads on the foot mechanics within each leg, an effect of different loads on the foot mechanics between the legs, and effects of covariates on the foot mechanics were examined. Limited studies have looked into the changes that take place on the foot to ground contact in asymmetric load-carrying such as carrying weight among healthy individuals. This study is aimed at quantitatively characterizing the biomechanics features of both right and left leg to ground contact (PP, MF, and CA) in different loads during standing and walking among healthy individuals. The knowledge on the loads exposed to the musculoskeletal system in asymmetrical load conditions may enable clinicians and researchers to make evidence-base choices on the safe and comfortable load carrying methods in an asymmetrical load condition with the purpose to prevent injuries.

The current study showed an increase in PP and MF in right leg during incremental loads when tested for the effect of incremental loads within both the legs. Previous study on obese subjects suggested an increase in PP due to the forward shifting of the center of the body.22 The forward shifting caused by the excessive adipose tissue carried by the musculoskeletal system further leading to increased foot loading. ${ }^{22}$ Another study on heavy backpacks reported that the head and trunk movements were coupled to counterbalance the load in the sagittal plane while walking, which leads to changes in foot to ground contact. ${ }^{23}$ The "motor control theory" explains that motor control is present to orient the body in its environment so it may maintain the posture to provide stability of the whole-body center of gravity. ${ }^{24}$ As such, the current study demonstrated that the body mid-line have shifted asymmetrically to the right of the frontal plane because the external load center of mass shifted laterally to the right from the body mid-line. ${ }^{13} \mathrm{As}$ 
such, the center of mass has shifted to the right side as the loads were carried using the right hand causing an increase in PP and MF in the right leg. Thus, individuals presenting with right side lower limb problem may consider carrying loads using the left hand and vice versa. This is to protect the affected tissues in the lower limb from more harm and injury due to the external load carried on the damaged side.

A significant increase of CA in the right leg during standing was observed when the effect of incremental loads within the legs was considered. This can be explained by the fact that the center of mass has shifted to the right side in response to the added loads and carrying using the right hand. The shifting to the right further leads to the increase in contact of the foot to the ground in the right leg. However, during walking, the CA of the right leg showed no significant differences, and the left leg showed a significant increase comparing right and left legs. This may be explained by the adaptive strategy in response to restore balance while walking. Previous studies on backpack load and position on posture reported that the body tries to restore the initial position of its center of mass to keep the posture inside the base of support for balance when the trunk leans forward. ${ }^{25,26}$ Similarly, in this study, the center of mass tends to shift in the direction of the carried load as explained in the "motor control theory." As such, one may change the walking pattern in such a way that there is a greater contribution of the left leg and more surfaces of the left leg are in contact to maintain balance and keep the posture inside the base of support. This pattern of adjustment is also seen in another study where the lateral movement of the body center of mass causes movement sideways towards the contralateral side to maintain stability. ${ }^{27}$

When the effect of the load was tested between right and left legs, the result showed that carrying a load of $10 \mathrm{~kg}$ when walking showed no significant difference in PP and MF. A previous study has reported shifting of the pressure to the heel because of the overuse of the forefoot during long-distance walking. ${ }^{2}$ This shifting of pressure to the heel was explained as a general change to avoid injuries, and even were observed in individuals without any foot complaints. ${ }^{2}$ Another study indicated that when walking at a high gait cadence while carrying a backpack, the reduction in ground reaction forces is a protective gait pattern adaptation as a consequence of load carrying ,aimed at minimizing possible harmful effects of high ground reaction force over the musculoskeletal system ${ }^{6}$. In the current study, subjects adapted their walking pattern in a way that the PP and MF of the right leg decreased (yet higher compared to left leg) through relatively increasing the PP and MF in the left leg to avoid overuse of the right leg and minimizing the risk of incurring right leg pain. Hence, shifting the loads to the left leg could be a defense mechanism, where overuse of the right leg during walking with $10 \mathrm{~kg}$ load becomes problematic. The increase of pressure and force on the left leg and the decrease of pressure and force on the right leg lead to a balance distribution of PP and MF on both the legs. This does not show a significant difference when observed between the right leg and the left leg.

There are few limitations in the present study. Firstly, the PP, MF, and CA while carrying loads using one hand usually occurs in the industrial setting or during daily life activity such as shopping. Therefore, the changes in foot mechanics with the shoes on may be different. As such, the study should be repeated using shoes to retrieve detailed information on the variations that occurs on the foot mechanics data. Secondly, the current study was laboratory based, and the data collection lasted for about one hour. In a real environment, the individuals may be standing and walking while carrying loads for longer periods. Thus, the current study result may not reflect the PP, MF, and CA changes when loads were carried for a longer period during standing and walking. Thirdly, the current study results may not be generalized to all healthy participants, as the results are confined to participants aged between 30 and 55 years old.

\section{CONCLUSION}

The present study looked into the effects of carrying weight with one hand unilaterally on the foot to ground relationship under the influence of different loads. The results suggest that when loads were carried using the right hand, there was an increase in PP, $\mathrm{MF}$, and CA in the right leg compared to the left leg. The results further suggest that the PP and MF increased incrementally in a load of $7.5 \mathrm{~kg}$ and $10 \mathrm{~kg}$ during standing and $7.5 \mathrm{~kg}$ during walking.

\section{References}

1. Jonely H, Brismée JM, Sizer PS, James CR. Relationships between clinical measures of static foot posture and plantar pressure during static standing and walking. Clin Biomech. 2011;26:873-9. http://dx.doi.org/10.1016/j.clinbiomech.2011.04.008. [PMID: 21632159]

2. Stolwijk NM, Duysens J, Louwerens JW, Keijsers NL. Plantar pressure changes after long distance walking. Med Sci Sports Exerc. 2010;42:2264-72. http://dx.doi.org/10.1249/mss.0b013e3181e305f4. [PMID: 20404764]

3. Deepashini H, Omar B, Paungmali A, Amaramalar N, Ohnmar H, Leonard J. An insight into the plantar pressure distribution of the foot in clinical practice: Narrative review. Pol Ann Med. 2014;21:51-6. http://dx.doi.org/10.1016/j.poamed.2014.03.003.

4. Deepashini H, Omar B, Paungmali A, Amaramalar SN, Ohnmar H, Leonard J. Reliability study of plantar pressure measurement among low back pain patients carrying different loads. Middle East J Sci Res. 2014;21:1044-50.

(C) The Internet Journal of Allied Health Sciences and Practice, 2017 
5. Putti AB, Arnold GP, Cochrane LA, Abboud RJ. Normal pressure values and repeatability of the Emed® ST4 system. Gait Posture. 2008;27:501-5. http://dx.doi.org/10.1016/j.gaitpost.2007.06.009. [PMID:17702582]

6. Castro MP, Figueiredo MC, Abreu S, Sousa H, Machado L, Santos R, Vilas-Boas JP. The influence of gait cadence on the ground reaction forces and plantar pressures during load carriage of young adults. Appl Ergon. 2015;49:41-6. http://dx.doi.org/10.1016/j.apergo.2015.01.004. [PMID: 25766421]

7. Castro M, Abreu S, Sousa H, Machado L, Santos R, Vilas-Boas JP. Ground reaction forces and plantar pressure distribution during occasional loaded gait. Appl Ergon. 2013;44:503-9. http://dx.doi.org/10.1016/j.apergo.2012.10.016. [PMID: 23157973]

8. Birrell SA, Haslam RA. The effect of load distribution within military load carriage systems on the kinetics of human gait. Appl Ergon. 2010;41:585-90. http://dx.doi.org/10.1016/j.apergo.2009.12.004. [PMID: 20060096]

9. Birrell SA, Hooper RH, Haslam RA. The effect of military load carriage on ground reaction forces. Gait Posture. 2007;26;6114. http://dx.doi.org/10.1016/j.gaitpost.2006.12.008. [PMID: 17337189]

10. Castro MP, Abreu S, Pinto V, Santos R, Machado L, Vaz M, Vilas-Boas JP. Influence of pressure relief insoles developed for loaded gait (backpackers and obese people) on plantar pressure distribution and ground reaction forces. Appl Ergon. 2014;45:1028-34. http://dx.doi.org/10.1016/j.apergo.2014.01.005. [PMID: 24468683]

11. Hong $Y$, Brueggemann GP. Changes in gait patterns in 10-year-old boys with increasing loads when walking on a treadmill. Gait Posture. 2000;11:254-9. http://dx.doi.org/10.1016/s0966-6362(00)00055-2. [PMID: 10802438]

12. Hong Y, Li JX. Influence of load and carrying methods on gait phase and ground reactions in children's stair walking. Gait Posture. 2005;22:63-68. http://dx.doi.org/10.1016/j.gaitpost.2004.07.001. [PMID: 15996594]

13. DeVita P, Hong D, Hamill J. Effects of asymmetric load carrying on the biomechanics of walking. J Biomech. 1991;24:111929. http://dx.doi.org/10.1016/0021-9290(91)90004-7. [PMID: 1769977]

14. Demura S, Uchiyama M. Effects of bag holding with one hand on lower leg muscles and postural control. Sport Sci Health. 2007;2:34-41. http://dx.doi.org/10.1007/s11332-007-0036-0.

15. Uchiyama M, Demura S, Shimada S, Yamada T. Effect of bag holding on upright postural control: an examination of center of foot pressure. J Educ Health Sci. 2005;50:180-9.

16. Bus SA, de Lange A. A comparison of the 1-step, 2-step, and 3-step protocols for obtaining barefoot plantar pressure data in the diabetic neuropathic foot. Clin Biomech. 2005;20:892-9. http://dx.doi.org/10.1016/j.clinbiomech.2005.05.004. [PMID: 15996799]

17. Zammit GV, Menz HB, Munteanu SE. Reliability of the TekScan MatScan(R) system for the measurement of plantar forces and pressures during barefoot level walking in healthy adults. J Foot Ankle Res. 2010;3:11. doi:10.1186/1757-1146-3-11. [PMID: 20565812]

18. Simoneau GG. Kinesiology of walking. In Neumann DA (Ed.). Kinesiology of the Musculoskeletal System: Foundations for Rehabilitation. 2010:627-81. St. Louis, MO: Mosby Elsevier.

19. Deng J, Joseph R, Wong CK. Reliability and validity of the sit-to-stand navicular drop test: Do static measures of navicular height relate to the dynamic navicular motion during gait. JSPTR. 2010;2:21-8.

20. Weiss L, DeForest B, Hammond K, Schilling B, Ferreira L. Reliability of goniometry-based Q-angle. Phys Med Rehabil. 2013;5:763-8. http://dx.doi.org/10.1016/j.pmrj.2013.03.023. [PMID: 23528815]

21. Cohen J. Set correlation and contingency tables. Appl Psychol Meas. 1988;12:425-34. http://dx.doi.org/10.1177/014662168801200410.

22. Teh E, Teng LF, Acharya R, Ha TP, Goh E, Min LC. Static and frequency domain analysis of plantar pressure distribution in obese and non-obese subjects. J Bodyw Mov Ther. 2006;10:127-33. http://dx.doi.org/10.1016/j.jbmt.2005.07.004.

23. Attwells RL, Birrell SA, Hooper RH, Mansfield NJ. Influence of carrying heavy loads on soldiers' posture, movements and gait. Ergon. 2006;49:1527-37. http://dx.doi.org/10.1080/00140130600757237. [PMID: 17050392]

24. Hong Y, Cheung CK. Gait and posture responses to backpack load during level walking in children. Gait Posture. 2003;17:2833. http://dx.doi.org/10.1016/s0966-6362(02)00050-4. [PMID: 12535723]

25. Brackley HM, Stevenson JM, Selinger JC. Effect of backpack load placement on posture and spinal curvature in prepubescent children. Work. 2009;323:351-60. https://dx.doi.org/10.3233/WOR-2009-0833. [PMID: 19369727]

26. Negrini S, Negrini A. Postural effects of symmetrical and asymmetrical loads on the spines of schoolchildren. Scoliosis. 2007;2:1-7. http://dx.doi.org/10.1186/1748-7161-2-8. [PMID: 17620121]

27. Crowe A, Schiereck $P$, Keessen W. Gait adaptations of young adult females to hand-held loads determined from ground reaction forces. Gait Posture. 1993;1:154-60. http://dx.doi.org/10.1016/0966-6362(93)90057-8. 